\title{
12 Generational analysis of the advanced welfare state
}

\author{
Asgeir Falch-Eriksen and Marianne Takle
}

\section{Introduction}

To study the advanced welfare state democracy through the prism of generation is a way to connect social change across time to tensions between the social reality of generations and the welfare state (Eisenstadt, 1971). As times pass, generations develop and change the normative composition of social order (Mannheim, 1952), and the welfare state must adequately addresses their needs and interests. Without such changes, tension might arise as a consequence of citizens in their capacity as a generation becoming governed by laws not suitable to their reasonable interests and needs. In a democracy, it is a fundamental principle of self-government that laws and regulations are authored by those who have to live by them if the system of government is to cash in on its promise of democratic legitimacy. If the generation, enforcement of welfare state policies, on the one hand, and their claim on upholding a democratic principle, on the other, have sparked tensions, then an approach that unravels tensions between generations and generations and the welfare state recommends itself for vigorous empirical analysis.

Central to the need for an increased focus on generations is also the increased rate of social change across time and how social change affects citizens in their capacity as social generations or kinships (Beck \& Beck-Gernsheim, 2009; Habermas, 2015). During the last 15 years, Europe has been through a financial crisis, increased immigration, and is currently locked down by the COVID-19 pandemic. Once the pandemic is over, society will again go back to the prevailing climate crisis. These are only the massive challenges ensuring social change. These are all the other effects of a globalized economy, new media, migration, international legal structure, the genuine global character of the economy, shifting loyalties across borders, etc. Challenges are lined up confronting generation after generation, and which also threaten the welfare state itself.

Moreover, the number of citizens affected by social change has not only increased, but these changes can leave a vast number of citizens at a detriment. The latter point fuses a generational analysis with a normative-critical aim in that detriment is sought avoided. Such an aim alludes to the resilience of a welfare state, the meaning of having it and the level of wellbeing it promises to uphold across generations (Goodin, 1988; Moon, 1988). Central to such an analytical 
approach is the role of time, and temporal location, either from the point of view of a birth year or from the point of view of different personal roles across a lifecourse (Wohl, 1979).

Across generations, citizens' private and family lives have gradually become symbiotically linked to advanced welfare states, and "needs-talk has been institutionalized as a major vocabulary of political discourse" (Fraser, 1989). How administrative bureaucracies have been coupled to welfare-state programmes depends on epistemic development and a highly educated workforce to meet generations' new needs and interests (Goodin, 1986). On the one hand, the welfare state has taken on tasks previously belonging to the private realm through administrative authority's coordinating forces (Habermas, 1990). On the other hand, the private domain engages according to a civic republican principle of self-rule to ensure collective problem-solving and coordination of the welfare state. The merge of these processes leads to the particular manner of self-government the welfare state represents.

The interpenetration of welfare state programmes into the private domain, and how it is continuously developed make a generational analysis of the welfare state increasingly relevant and also more complex. This is underlined as welfare state democracies have grown into mass societies, with a high degree of universalism and equal access as a matter of right (Goodin, 1986; Shapiro, 2007). The welfare state itself has changed the run of generations and, as stated, established a symbiotic relationship to individuals throughout their life-courses and the roles of generations (Bristow, 2016; Fraser, 1989).

The welfare state relates to individual citizens in their capacities as a member of different types of generations through their age and their generational roles: either as young, adult, or old; working age; as born a specific year; as a parent; a mother; or a grandfather (Eisenstadt, 1971). By viewing the democratic welfare state as a response to generations' needs and interests, the welfare state becomes linked to different concepts of generation, which further makes such a concept fruitful for generational analysis (Bristow, 2016). This is crucial because many challenges to the welfare state have different consequences depending on what generation a citizen belongs to. To the equation of the increasingly complex welfare state system within democracies and its interconnectedness with its citizens' private lives, tensions become a pulse of how well the welfare state system develops. If tensions abound, the system designs of government are flawed itself. Still, if tensions are addressed and met continuously, the welfare state works according to its democratic intent as part of everyday politics.

\section{Generation concepts in welfare state studies}

In this volume, we have applied four different types of generations: social generation, kinship generation, historical generation, and future generation. Our analyses take one or more of these concepts as a point of departure and studies what tensions arise within the welfare state. This can include tensions between generations or between different generations and the welfare state and its relation to 
social change or pressures. To each of the generation types, we can point towards specific conceptual links to the welfare state.

Social generations are understood as socially embedded birth cohorts inserted into what Mannheim refers to as the "social interrelationships in their historic flux" (Mannheim, 1952). This implies sharing the same temporal location and historical, cultural conditions, and processes with equal age peers. As the welfare state gradually has created increasingly more complex bonds between citizens, and between the state and citizens, so has each social generation through time become increasingly interconnected with the normative-political construct of the nation-state, and made the welfare state an intricate part of citizen's identity and how they chose to live life. Thereby, as time has gone by, a welfare state democracy has become solidified through public approval (Banting \& Kymlicka, 2017).

The welfare state is not only merged into citizen's way of life, thoroughly affecting each social generation as they age (Fraser, 1989), but it is also designed to a certain extent to meet different generation-specific challenges. Concerning social generations, it becomes a matter of age-specific policies and welfare state programmes. As shown in Chapter 3, problematizing generational conflicts between the young and the elderly concerning family- or pension benefits, agespecific benefits receive support across social generations.

Typically, following social generations as birth cohorts, or conjoined birth cohorts into clusters of social generations, can teach us lessons of why certain social generations fared better than others, as shown in Chapter 7, where different sets of social generations through time show how public efforts to combat marginalization and social inequality has been less efficient and that new approaches are needed to reduce marginalization and ensure social inclusion.

Kinship generations involve the local community's generation complex that individuals are born into, and its nucleus is the hierarchical parent-child relationship (Pilcher, 1994). However, kinship denotes more than a biological bond between generations; it also involves the family and social communities where the family is socially embedded. Within kinships, a member has different roles and different expectations towards the welfare state. As with social generations, kinships have many generation-relevant challenges in their interconnection to the welfare state. For instance, Chapter 5 shows how challenges arise towards parents' formative role in child-rearing, particularly how migrant parents struggle with child-rearing expectations. From this volume, we can learn the traditional manner in which generations within families define roles and work together to seek a life independently.

Social generations and kinship generations, although conceptually separated, are intertwined in that citizens belong to both, one way or the other. As the welfare state can be viewed as a product of what Habermas refers to as the colonization of the lifeworld, what belonged to the lifeworld of traditional societies, and especially to conduct social control and secure social integration, is gradually transferred to the administrative state by way of the steering media of power (Habermas, 1990). Hence, as a welfare state democracy, and with its purposiverational logic, aimed at taking over traditional tasks of the family and kinship, and 
thereby making the welfare state into a socially coordinating mechanism, it affects citizens in their capacities as both social generation and kinship differently. As a family member, what defined kinship roles, gender, class, and ethnicity becomes interlocked with the faith of what social generation you belonged to. As shown in Chapter 6, they find that young adults who want to become homeowners still become homeowners irrespective of policies that restrict mortgage-lending and the increase in house prices, all while not receiving inter-familial transfers of money from parents.

Historical generations involve using labels to denote a specific trait with certain age cohorts. These labels are often applied to describe what Mannheim refers to as a generational style of generational units, depicting the dominating part of a social generation that ensures social change (Mannheim, 1952). What is implied is to label the driving force within a series of social generations, which generates either a phenomenon or a social change. Historical generations are qualified through historical research and where the members of the social generations would subscribe to. Purely ascriptive generations should be avoided, that is, the use of labels that are merely ascribed to specific birth cohorts to capture specific changes or phenomenon.

As we show in this volume, Boomers in Chapter 9 and Digital generations in Chapter 8 are examples of historical generations, while the labelling of Millennials and generation $\mathrm{Z}$ in Chapter 10 are examples of ascriptive generations. From these chapters, we learn about the historical generations, which typically denominate a set of conjoining social generations that signify social change or represent a particular phenomenon. After studying social change and social generations, these labels are applied to general trends in the welfare state's development. What we can do today, compared to what Mannheim practically could do, is to locate generational units and generational styles that are more subtle. Hence, labels can be a tool to describe how social generations cope through time. Furthermore, labels can capture how certain social generations experienced, and with a formative impact, welfare state legislation, policies, and street-level efforts.

Future generations cannot be studied per se, but applying such a perspective establishes an analytical tool for the analysis of sustainability and resilience of the welfare state, and what is called upon to ensure the prevalence of the standard of wellbeing across time. From such a perspective, one can alternate or combine the social generation analysis with kinship analysis. This means that the challenges to future generations are the current generation's priority of those who are not yet born (Tremmel, 2009). As we show in Chapter 4, such priorities are contested, and the time aspect is crucial. By giving priority to the wellbeing of people who are not yet born, one accentuates the future rather than the historical traditions, which the national welfare state builds on. The concept of future generations involves a future-oriented mindset that will become more important as people who will be born in the future will be increasingly dependent on current democratic decision-making controlling for ecological limitations. 


\section{Why generational analysis?}

A generational perspective to studying advanced welfare states is critical because of at least four interconnected societal phenomena. The first is the character of each citizen's needs and interests in their capacity to be part of a generation. The needs and interests of generations can be assumed are the sum of all individuals of similar age at one specific age that are predominantly rationally motivated to reach decisions on what is in their own best interests, and would want to engage in public discourse on how the welfare state works according to their own reasonable claims (Heath, 2001; Moon, 1988; Thompson, 1988). We can thereby speak of generational self-interest, which is how a social generation's needs and interests can develop across time throughout life-courses, change in character, and eventually stand in a potential tension or conflict with other generations or with the welfare state itself as to how their interests and needs are met.

Over time, as new age cohorts reach a specific age, their needs and interests can have changed compared to earlier age cohorts when those cohorts were at the same age, leaving the welfare state in slight disharmony with citizens' expectations from one generation to the next. As a welfare state is designed to meet certain needs and interests and uphold certain stabilized expectations and not others, how such policies and programmes are designed becomes both a product of the time they are implemented and the generations responsible for designing them. Some policies and programmes that were in harmony with the expectations of those affected by them at one moment in time can be in disharmony as time goes by and new generations come through. As an engine of social change, generational self-interest can spark the need for change and development of the welfare state.

The second is that risks confront individuals across generations differently (Beck, 2013; Habermas, 2013). If you are a young child, you will be differently affected by massive societal events than, for instance, an elderly. Either it is a financial crisis, increased migration, climate change, or a pandemic, and many of them simultaneously can have profound impacts across concurrent generations. As time has progressed, crisis and risk have become a large part of societal challenges facing both the welfare state and the generations within it in different ways. For instance, many European countries were affected harshly by the financial crisis in 2008, and austerity measures followed. This means that certain generations might have needs that are not met by the welfare state where it used to because the welfare state simply cannot deliver.

Another example is the COVID-19 pandemic, which clearly will impact certain generations more than others. Social changes are massive, where working generations are losing employment, children are in lockdown for months at the time, and work-life is going digital at record speed. The welfare state was never prepared for answering each of these generational needs. Hence, there is a difference between the social reality of behavioural expectations of the generations experiencing detriment and what the welfare state can. This eventually alludes to the wellbeing a welfare state is set to guarantee and what is actually provided. 
If the discrepancy is too large and the welfare state does not provide what it is designed to provide, tensions will rise, and conflicts may occur.

Third, the pace of social change is significantly driven by combined digitalization processes and globalization. Mannheim (1952) was concerned with the importance of the acceleration of social change for the realization of the potential in the generational location. He contended that slowly changing communities have no new generational unit sharply set off from the predecessors, while too greatly accelerated tempo might lead to mutual destruction of the generational units (Mannheim, 1952). However, the current tempo of social change is faster than ever. This leads to the spread of norms and expectations that form generations across the world, which might lead to the development of a kind of "global generation" (Beck \& Beck-Gernsheim, 2009).

Fourth, the increase in complexity and pluralism implies the growth of the number and variety of action norms that individuals can choose from (Giddens, 1991; Rawls, 1993). Processes of modernization and work differentiation cause social complexity. These processes ensure the differentiation of functional spheres that organize social reproduction. Examples of such spheres are economy, educational systems, and welfare state politics. Individuals provide the increase in pluralism as they exercise their right to choose how to live their lives freely and the migration of individuals and cultural ideas that become increasingly inserted into the social fabric. This can create needs that did not use to be there, but need a welfare state can be expected to meet (Goodin, 1986). The outcome is a steady growth in the number of viable action norms within societal order. Hence, what binds society together becomes more complex.

Each of these societal phenomena, but also various combinations of them, develops tensions that confront the everyday lives of citizens and sparks change. They can also have devastating consequences to the resilience of the democratic welfare state and how it copes with addressing the needs and interests of citizens in the future. Yet, how different generations are affected by and cope with meeting these challenges is at the core of social change and self-government. Studies of social change, value transmission, social mobility, and the cultural and social integration of immigrants must cope with generational relations. What is crucial to such studies' future, though, is that the generational approach is applied with generation as a multifaceted concept, pertaining to all aspects of life where individuals take part in a generation. In this manner, a generational approach can become a prism for analysis.

\section{Where to apply a generational analysis}

By being allowed to go deeper into how generations cope within the welfare state, irrespective of what concept of generation you carry into analysis, we can unveil tensions and unmask the needs and interests of new generations that were not there earlier. We can follow generational changes, how transitions go by on a much smaller level than earlier. For instance, incremental social changes from one social generation to the next, but that becomes large in a decade, incremental 
changes in role patterns in kinships, how certain roles differentiate (among, e.g. mothers, child, elderly), unmasking increases in needs from one generation to the next. By applying different generations' concepts, we can measure generational changes in every crits and cranny of the welfare state.

Hence, the social change occurring on a generational level, although small, can be located and studied, if not to unveil how generations are inserted into welfare states and how the welfare state affects certain generations, but to critically study to help solve challenges facing advanced welfare states to salvage it when faced with tensions and significant conflicts. A generational approach thereby lends itself to an increasingly more advanced study of welfare state development. We can briefly illustrate four central areas of where to apply generation analysis:

1. Legal development and implementation: Between where citizens reside in social reality as part of a generation and the advanced welfare state is a democratic legal form that can bridge the alleged will-of-the-people within the societal order to the legal architecture of the welfare state as it is developed through democratic law-making. Democratic law-making stands to be imperative in aligning political solidarity with social solidarity carried across generations; how laws are developed, enacted, and implemented becomes crucial for each generation inserted into the social fabric. As time goes by and new generations reach new life phases and become addressed by the welfare state, tensions may arise between stabilized legal norms that carry the welfare state policies or programmes and reasonable expectations towards the welfare state. If the tensions become too large, the democratic legitimacy the welfare state depends on becomes questioned.

2. Policy analysis: By applying a generational approach to welfare state policies, it is first and foremost to study "public agency over activities that are socially valued", and that can affect any kind of generation (Selznick, 1985). Policies can affect kinship generations differently than different social generations, and also, future generations can, as they often are, be omitted from policy considerations altogether. In advanced welfare states, we must consider that public policies operate in complex organizations within even more complex social systems. This can imply, among other things, that policies often cross sectors, they involve plenty of efforts within organizations and among personnel, have no definite scope but are somewhat vague and openended, the purpose and aim may change over time, thrust is caused by a web of decisions in a network of decision-makers, they can materialize in organizations or regulation. They may also consist of non-decisions (Hill, 2005). In brief, how policies affect generations can vary and spark different types of tensions that must be mediated to avoid erosion of solidarity within the political construct of the welfare state.

3. Professional practice and service designs: Most of the welfare state's distribution of goods and services are effectuated through decision-making by professional practitioners on street- level and who meet the service users, the user groups, and the clients (Elster, 1992; Lipsky, 2010). A great deal 
of the potential of a welfare state and how it addresses its citizens' needs as part of generations are achieved on street-level. It can be the social worker, the medical practitioner, or the teacher, but they all work on street-level and distribute welfare state resources. As most professional practices claim to be knowledge-driven and belonging to welfare state bureaucracies, professions are the toolbox of a welfare state and how it addresses needs and defines needs (Goodin, 1986).

4. Societal challenges: The last areas we will point at are the societal challenges that citizens are concerned with and that challenge their daily lives. They are either elderly, youth, migrants, women, poor, drug users, or people with disabilities or health problems; to map and unveil how their lives progress defines the needs of the welfare state, and it is imperative for the welfare state to address needs and interests as they are carried by those affected rather than those who designed the policy or the programme. Hence, if the welfare state does not redesign, continue to adapt, it will fail to provide for those who carry reasonable needs and interests.

\section{Solidarity in advanced welfare states}

Solidarity, irrespective of how deep it runs, establishes some level of interconnectedness to other individuals belonging to a collective social order, a "we" that persists across generations and that new generations become introduced to (Heath, 2001). Solidarity thereby involves some level of mutual recognition, and a continuous inclusion of new generations into a civic culture with civic engagement through public use of individual autonomy to "share in governing a political community that controls its fate. Self-government in this sense requires political communities that control their destinies" (Sandel, 1998).

Our point of departure is that democratic governance is at the heart of what makes a generational approach central to understanding how the welfare state works and how it is kept resilient despite social change, tension, conflict, and crisis. A legally regulated welfare state system, where societal norms are stabilized into legal form and through implementation, brings out the internal and necessary tension between the welfare state system and the fluctuation in the societal system it governs (Habermas, 1998). The tension alludes to the dynamics of the democratic rule of law and the potential disintegration between the positivity of the legal order and government and what is expected from the point of view of social solidarity.

A welfare state democracy is set to respond to citizens' needs and interests in their capacity to belong to social generation or kinship generation. Implicit to any type of democratic governance, which constitutionally guarantees each citizen equal access to self-governance, has the potential of crafting legislation, developing regulation, and ensuring implementation that politically aligns with the type of solidarity that defines the normative composition of societal order. Through democratically enacted legislation, the promise of democracy is to let a civic republican principle of popular sovereignty govern how new legislation 
and regulation comes about as a matter of collective self-realization and self-rule (Banting \& Kymlicka, 2017). If such a fundamental principle is upheld, the welfare state can be understood as the product of generations' needs as they progress through time. Social solidarity, then, can be crafted into a stabilized representation-dubbed political solidarity (Rehg, 1994).

Treating the welfare state as a constitutional democracy that combines self-rule with the protection of each citizen's fundamental rights is to embed a counterfactual into what generation analysis is about. Perfect welfare democracies do not exist. However, every advanced welfare state democracy carries these ideals as a constitutional backbone to how collective coordination and problem-solving is supposed to work. It opens up the approach to critically investigate how a welfare state fares concerning allowing generations' access to self-rule and see whether their interests are given due weight or not. Most likely, certain generations will have a more significant influence than others. We could even expect certain blind spots of generations lacking welfare state services to their fullest extent as they are not politically engaged. This is, in particular, the case with children and elderly, who constantly are not represented as themselves but are at the mercy of others claiming to channel their needs and interests.

The motivation of each individual's public engagement is what establishes the bridge between the negative liberty of each, where its personal preferences reside, and are acted upon privately, to the positive liberty through the individual's "public use of reason" (public autonomy) (Berlin, 1958). Acting upon positive liberty is when each individual is partaking in social solidarity and accepts the liberal ethos of basic freedoms, something that implies a right to remain solidaristic on the one side, guided by certain collective actions, but on the other have the right to remain strangers to one another if that is the choice. This type of republicanism is very often the case in major advanced welfare states, namely that citizens have the right to choose for themselves how to live their lives and also how to engage in self-rule through public discourse, voting, representation, and so on (Habermas, 1996; Thompson, 1988).

\section{Tensions between social reality and the welfare state}

Several generational studies have focused on tensions and conflicts between generations. While Mannheim concentrates on the role of social change through generations, conflicts and tensions are at the core of Norbert Elias' studies (Connolly, 2019). Elias (2013) shows how tensions and conflicts arise between generations through the opening or closing of channels for young people's opportunities, in terms of life opportunities, meaning, and upward mobility. He sees these as an outcome of societal change in which wars, revolutions, economic development, and peace are central (Elias 2013).

In this volume, we concentrate on tensions and less on conflicts, by toning down the level of friction and disagreement as definitional traits of social generations. We instead identify and explain social change as a consequence of tensions between generations and between generations and the welfare state that are to 
be expected within pluralistic and complex modern welfare state democracies. The challenges to the contemporary welfare state, albeit very consequential, have fewer leading to full-out conflicts between generations or between generations and the welfare state, such as the youth rebellion in the 1960s. In contrast, social changes are incremental, and the tensions that arise have normally minor consequences for the welfare state.

To what extent and how can tensions be good if we strive for a solidaristic welfare state? To illuminate this, our point of departure is how the welfare state is the outcome of democratic self-governance. A democratic welfare state, in an ideal sense, is set to affect each individual equally according to a formal principle of law (Goodin, 1988; Rothstein, 1998). This implies that not only are laws, regulations, and implementation meant to affect equally in equal cases and unequally in unequal cases, according to a principle of law, but also the democratic ethos suggests the welfare state is supposed to meet the interests and needs of its citizen continuously and irrespective of what social generation the citizen belongs to (Dahl, 1983).

On the one hand, as the welfare state provides services, it meets a fixed generational need and interest, specified into the welfare state construct as a stabilized fixed norm. On the other hand, those who carry interests and needs carry them irrespective of a welfare state and do so from a flexible social reality, one that does not necessarily correspond to what the welfare state does. The distance between what the welfare state responds to of interests and needs through its regulatory programmes and policies and what constitutes the social reality of generations' interests and needs becomes an indicator of tension. The further away a welfare state democracy is from adhering to the needs and interests of certain generations, which is a social reality that a welfare state's normative core purpose is set to respond to, the more tensions there are. A similar use of the duality between social reality and regulation is often used by legal scholars such as Habermas (1996). Still, here we transfer the same duality from the legal system alone onto a broader concept of a welfare state governed by the rule of law, welfare state programmes, policies and complex welfare services, and street-level bureaucracy.

As social norms always are in flux and potentially can create tensions, each social generation is expected to be represented in democratic public discourse on welfare state programmes and policies and contribute to altering how the welfare state works by aligning the political order of the welfare state to fit the social reality it governs. Of course, this is an ideal and counterfactual view of how welfare state democracies works, but these principles of democracy, representation, and citizenship nevertheless constitute an ideal most advanced welfare states democracies subscribe to and which they are very often formally obligated to abide by through constitutionally established principles of democracy and popular sovereignty and human rights (Rothstein, 1998; Thompson, 1988).

The opposite of tension is when the social solidarity and political solidarity are aligned and that the welfare state operates according to expectations. This is hard, if not impossible, to achieve perfectly due to the constant fluctuation of social reality. However, democratic rule-of-law as a legal form carries a potential 
for a driving thrust to stabilize generalized behavioural expectations into the legal order through political craftsmanship (Habermas, 1996). Hence, a principle of popular sovereignty has built into itself the potential for establishing harmony. It is a function of mechanisms pertaining to the role of democracy and the normative intent of having democracy altogether, namely to secure the self-government of the people (Thompson, 1988).

To reiterate, as generations progress through time, any given generation will carry with them certain alterations of how they expect a welfare state to work and what a welfare state is set to alleviate. Over time, and as new generations continuously come along and gradually eschew the tension between what is reasonably expected from a welfare state and what the welfare state provides, a welfare state democracy gradually loses its claim to legitimacy as it does not respond to those it governs. The opposite can also happen, namely that the tension can also be alleviated from one generation to the next. However, over time, social change is expected, and corresponding welfare state schemes' changes are called upon. In this manner, how tension develops across time, how it is democratically addressed has been a core engine of welfare state development (Kumlin \& Rothstein, 2005; Rothstein \& Steinmo, 2016). What constituted a discrepancy that past generations democratically sought to engage and address established a specific welfare state policy that in itself can lead to tensions as new generations that carry a new version of social reality are addressed by the welfare state. For democratic rule-of-law to once again govern the new generations, these tensions, wherever they are, must be alleviated and once again become aligned with the societal norms that exist within the social system the welfare state is set to serve (Habermas, 1996).

\section{Generations at the genesis of the welfare state}

As long as there are tensions between what is reasonably expected from a generation towards the welfare state and what the welfare state provides, the welfare state is not aligned with the solidarity it draws upon in legitimizing welfare state programmes and policies as democratically imposed. To reach such an end, selfgovernment must redesign and continue to develop to fit the needs and interests of concurrent generations as they develop over time. The redistribution of goods and services addressing needs and interests of citizens throughout their life-course and in their generational life-phase capacities as child, parent, working-age, or retired, establishes an interconnection between the generation a citizen belongs to, and the advanced welfare state democracy. As a welfare state is structured around the needs and interests of different types of generations and the role it plays in redistributing goods and services to meet these needs and interests, we should also accept the call for a more precise research agenda applying generational analysis. The aim is to better inform welfare state policies and programmes about challenges ahead, potential conflicts, and ongoing tensions. Citizens' needs and interests will remain predictably related to the type of generation the citizens fit into, albeit the very role of generations might shift. As welfare states 
can be argued to answer the needs and interests of a citizens' generation, we can argue that the welfare state also can be explained according to a generational perspective.

The opposite seems rather to be the normal case, namely that welfare state research seeks to understand how the welfare state impacts generations (See, for instance, Birnbaum et al., 2017; Daly, 2020; Riekhoff, 2020). This research is obviously valuable, but it is not applying a generational perspective to draw specific lessons from the welfare state pertaining to generations itself. Not only does it reverse what is explained with what explains, but it also runs the possibility of disconnecting the welfare state from its societal foundation and the citizens who feed into it through self-government. Applying a generational perspective implicitly treats the welfare state as intrinsically linked to how individuals live their lives and choose to coordinate and solve problems collectively across generations, hence, providing both meaning and purpose to undertaking generational analysis. The generational approach increases in strength through a principle of popular sovereignty and the interconnection it establishes to the welfare state democracy from the perspective of social order. This argument holds merits irrespective of what type of democracy we are speaking of, whether it leans towards, e.g. communitarianism or cosmopolitanism.

This volume has attempted to draw attention to an approach to study the advanced welfare state that speaks directly to much of the purpose of having a welfare state altogether - namely to serve individuals as they pass through life, with their age-relative needs and interests. To concentrate on doing so implies an attempt at kickstarting a research agenda using various concepts of generation as the point of departure for analysis.

\section{References}

Banting, K., \& Kymlicka, W. (2017). The strains of commitment: The political sources of solidarity in diverse societies. Oxford University Press.

Beck, U. (2013). Risk, class, crisis, hazards and cosmopolitan solidarity/risk communityconceptual and methodological clarifications.

Beck, U., \& Beck-Gernsheim, E. (2009). Global generations and the trap of methodological nationalism for a cosmopolitan turn in the sociology of youth and generation. European Sociological Review, 25(1), 25-36.

Berlin, I. (1958). Two concepts of liberty. An Inaugural Lecture delivered before the University of Oxford on 31 October 1958. Clarendon.

Birnbaum, S., Ferrarini, T., \& Nelson, K. (2017). The generational welfare contract: Justice, institutions and outcomes. Edward Elgar Publishing.

Bristow, J. (2016). The sociology of generations: New directions and challenges. Springer.

Connolly, J. (2019). Generational conflict and the sociology of generations: Mannheim and Elias reconsidered. Theory, Culture \& Society, 36(7-8), 153-172.

Dahl, R. A. (1983). Dilemmas of pluralist democracy: Autonomy vs. control. Yale University Press.

Daly, M. (2020). Generations, age and life course: Towards an integral social policy framework of analysis. Contemporary Social Science, 15(3), 291-301. 
Eisenstadt, S. N. (1971). From generation to generation: Age groups and social structure. Transaction Publishers.

Elias, N. (2013). Studies on the Germans: Power Struggles and the Development of Habitus in the Nineteenth and Twentieth Centuries. University College Dublin Press.

Elster, J. (1992). Local justice: How institutions allocate scarce goods and necessary burdens. Cambridge University Press.

Fraser, N. (1989). Talking about needs: Interpretive contests as political conflicts in welfare-state societies. Ethics, 99(2), 291-313. https://doi.org/10.1086/293067

Giddens, A. (1991). Modernity and self-identity: Self and society in the late modern age. Polity Press.

Goodin, R. (1986). Welfare, rights and discretion. Oxford Journal of Legal Studies, 6(2), 232-261.

Goodin, R. (1988). Reasons for welfare: The political theory of the welfare state. Princeton University Press.

Habermas, J. (1990). Moral consciousness and communicative action. Polity Press.

Habermas, J. (1996). Between Facts and Norms. Contributions to a Discourse Theory of Law and Democracy (W. Rehg, Trans.). The MIT Press.

Habermas, J. (1998). Inclusion of the other: Studies in political theory. The MIT Press, Cambridge, MA.

Habermas, J. (2013). Democracy, solidarity and the European crisis. Roadmap to a social Europe, 4.

Habermas, J. (2015). The lure of technocracy. John Wiley \& Sons.

Heath, J. (2001). Communicative action and rational choice. MIT Press.

Hill, M. (2005). The public policy process. Pearson Longman.

Kumlin, S., \& Rothstein, B. (2005). Making and breaking social capital: The impact of welfare-state institutions. Comparative Political Studies, 38(May), 339-365.

Lipsky, M. (2010). Street-level bureaucracy: Dilemmas of the individual in public service. Russell Sage Foundation.

Mannheim, K. (1952). Essays on the sociology of knowledge. Routledge and Kegan Paul Ltd.

Moon, J. (1988). Democracy and the welfare state. In G. Amy (Ed.), 2. The moral basis of the democratic welfare state (pp. 27-52). Princeton University Press. https://doi.org/doi :10.1515/9780691217956-005

Pilcher, J. (1994). Mannheim's sociology of generations: An undervalued legacy. British Journal of Sociology, 45, 481-495.

Rawls, J. (1993). Political liberalism. Columbia University Press.

Rehg, W. (1994). Insight and solidarity: The discourse ethics of Jürgen Habermas. University of California Press.

Riekhoff, A. J. (2020). Pension reforms, the generational welfare contract and preferences for pro-old welfare policies in Europe. Social Policy \& Administration, 55.

Rothstein, B. (1998). Just institutions matter. The moral and political logic of the universal welfare state. Cambridge University Press.

Rothstein, B., \& Steinmo, S. (2016). Restructuring the welfare state: Political institutions and policy change. Springer.

Sandel, M. J. (1998). Democracy's discontent: America in search of a public philosophy. Harvard University Press.

Selznick, P. (1985). Focusing organizational research on regulation. Regulatory Policy and the Social Sciences, 1, 363-367.

Shapiro, D. (2007). Is the welfare state justified? Cambridge University Press. 


\section{Asgeir Falch-Eriksen and Marianne Takle}

Thompson, D. (1988). 6. Representatives in the welfare state. In A. Gutmann (Ed.), Democracy and the welfare state (pp. 131-156). Princeton University Press.

Tremmel, J. C. (2009). A theory of intergenerational justice. Routledge.

Wohl, R. (1979). The generation of 1914. Harvard University Press. 